\title{
Effect of a Nurse Back Injury Prevention Intervention on the Rate of Injury Compensation Claims
}

\author{
Peter J. Martin ${ }^{a}$, Jack T. Harvey ${ }^{a, b}, *$, John F. Culvenor ${ }^{c}$, Warren R. Payne ${ }^{b}$ \\ a School of Information Technology and Mathematical Sciences, University of Ballarat, Australia \\ b School of Human Movement and Sport Sciences, University of Ballarat, Australia \\ c VIOSH Australia, University of Ballarat, Australia
}

\section{A R T I C L E I N F O}

\section{Article history:}

Received 21 August 2007

Received in revised form 30 September 2008

Accepted 27 October 2008

Available online $\mathrm{xxxx}$

\section{Keywords:}

Nursing

Back injury

No lifting

Longitudinal analysis

Evaluation of occupational health and

safety interventions

\section{The Problem}

Back injuries among nurses are associated with the high physical loads involved in manual lifting and transferring of patients (Engkvist, Hagberg, Linden, \& Malker, 1992). While behavioral interventions have been effective in reducing injury rates in a number of other industries (Krause, Seymour, \& Sloat, 1999), the approach of teaching safe manual handling techniques to nurses has been ineffective in reducing the risk of injuries (Carlton, 1987; Department of Human Services, 2002). Garg, Owen, and Olsen (1992) identified many of the factors associated with failures in previous approaches to manual handling among nurses. Given the reported failures of "safe lifting" approaches, the Victorian Nurses Back Injury Prevention Project (VNBIPP) sought to bring about changes in the physical workload, by replacing manual lifting and transferring of patients with modern hoists and other patient transfer devices. The VNBIPP was based upon no lifting principles found in programs developed by the Royal College of Nursing (1999a,b), which had informed the No Lifting policy of the Australian Nursing Federation (ANF) and had been implemented in individual Australian hospitals (Garrison, 1998; Gorman, 1998). Guidelines for the implementation of No Lifting programs were developed by the Royal College of Nursing (1999a,

* Corresponding author. School of Human Movement and Sport Sciences, University of Ballarat, PO Box 663 BALLARAT Victoria 3350, Australia. Tel.: +613 53279065; fax: +613 53279478 .

E-mail address: j.harvey@ballarat.edu.au (J.T. Harvey). b) and the Occupational Safety and Health Administration (Feletto \& Graze, 1997; OSHA, 2003) and have been implemented in nursing homes and hospitals (Australian Nursing Federation, 2003; Garg, 1999).

Studies of the effectiveness of No Lifting policies have been reported in health industry documents (Ashford, Sdrinis, \& Doyle, 2003; Engkvist, 2001; Gaetjens, 2003; OSHA, 2003) and the peer reviewed literature (Collins, Wolf, Bell, \& Evanoff, 2004; Engkvist, 2004; Passfield, Marshall, \& Adams, 2003). No Lifting policies have resulted in reductions in the occurrence of back injuries (Ashford et al., 2003; Collins et al., 2004; Engkvist, 2001; OSHA, 2003; Passfield et al., 2003) of up to $71 \%$ (Ashford et al., 2003). Workers compensation claims have also been reduced (Ashford et al., 2003; Collins et al., 2004; OSHA, 2003; Passfield et al., 2003) by up to 97\% (OHSA, 2003). Other studies have explored factors associated with the onset of back injuries such as access to employee training and the effect of inter personal conflict on workers compensation claim rates (Gaetjens, 2003).

In general, these studies have been single institution case studies (Engkvist, 2001; OSHA, 2003; Passfield et al., 2003) or have covered a relatively small cluster of institutions (Ashford et al., 2003; Collins et al., 2004; Engkvist, 2004). While the results obtained in these relatively small scale studies are impressive, the question remains as to whether similar results can be obtained when implementing a No Lifting policy across an entire health care system, where inhe rent variations in management and practice might be expected to exist across the system. Following an earlier preliminary evaluation (Department of Human Services, 2002), the purpose of this study was 
to carry out a retrospective evaluation of the VNBIPP, which involved the implementation of a No Lifting policy across an entire health care system. Specifically, the study sought to determine whether the im plementation of the policy had resulted in a significant reduction in the workers compensation claim rate for back injuries. The progres sive nature of the implementation of the intervention, together with particular characteristics and limitations of the retrospective data, required the development of novel analytical methods.

\section{Method}

The system wide nature of the intervention and the retrospective nature of the study limited the scope and quality of available data and presented a number of methodological challenges. In spite of these limitations, the analytical approach presented extends the typical evaluation methodology beyond the straightforward pre post com parisons appropriate for a short term well defined intervention, to include a consideration of trends before, during, and after an in tervention, which is widely distributed in organizational scope and is implemented progressively.

\subsection{Study Location and Scope}

The study covered all agencies in the Victorian public health care sector for the period 1998 to 2004 . A total of 111 agencies were funded under the VNBIPP, but at the time of the study, restructures and amalgamations had reduced this to 92 agencies. Approval to conduct the study was granted by the University Human Research Ethics Committee.

\subsection{The Victorian Nurses Back Injury Prevention Project}

The VNBIPP was based on the No Lifting policy of the Victorian Branch of the Australian Nursing Federation, which was derived from a model developed by the Royal College of Nursing in the United Kingdom (Australian Nursing Federation, 2003). The Victorian De partment of Human Services (DHS) provided A $\$ 8.35$ million over four funding rounds during the 19982004 period. This constituted one of the largest single investments in a risk control intervention in the history of occupational health and safety $(\mathrm{OH} \& \mathrm{~S})$ in Australia.

The project was directed at eliminating or minimizing manual handling when moving patients. This was achieved through the pro vision of patient handling aids and equipment, education in No Lift ing principles and techniques, and by encouraging cultural change and ownership by nurses. Aspects included raising the awareness of nurses, encouraging nurses to be proactive in identifying hazards, educating nurses in patient risk assessment, encouraging patient independence and mobility, and encouraging patients to assist in their own transfers. Additionally, organizational commitment was sought at all levels to facilitate long term cultural change.

\subsection{Data Sources}

Data regarding DHS funding and compensation data from the Victorian WorkCover Authority (VWA) provided a consistent basis for longitudinal analysis. A survey was used to gather supplementary data about the workforce and details of program implementation and ex penditure from individual agencies.

Because the VNBIPP was in many cases implemented in specific wards or sections within agencies, it would have been desirable to base the analysis at the ward level. However, VWA and individual agencies could not provide data at this level. Consequently, data at the level of campus or workplace were used.

\subsection{Victorian WorkCover Authority (VWA) Data}

Standard claims data were obtained from VWA. A standard claim is one where either a worker requires at least 10 days off work, or medical and related expenses exceed a threshold value (A $\$ 495$ at the time of the study). Common law claims were included in these data but not identified. VWA provided the research team with three major data sets.

1. Total remuneration and premiums by current workplace address by financial year (1993/1994 to 2002/2003). No indexation was ap plied by VWA to these data.

2. Standard claim information for claims reported from July 1993 to June 2003 (details as at August 31, 2003).

3. Dictionary of claim codes for mechanism of injury, nature of injury/ disease, bodily location, agency of injury, and occupation.

Various adjustments such as re assignment of data from prede cessor organizations were made by VWA so that the historical data could be meaningfully compared to the more recent data.

Relevant VWA codes were used to define Nurses, Back Injuries, Neck/Shoulder Injuries, and Wrist/Knee/Ankle Injuries. The latter two categories were used to provide control data against which trends in back injuries could be compared.

\subsection{Agency Survey Data}

A survey was sent to 92 agencies via email and included an in troductory letter and a spreadsheet designed to capture: (a) details of key staff, (b) campus descriptors, (c) VNBIPP funding and expenditure details by campus and financial year, (d) annual estimates for each campus of staff numbers and hours worked, and (e) an equipment audit for each campus.

After multiple follow up emails and telephone calls over two months, returns were received from 52 agencies. Many of the agencies had difficulties in providing information because of: (a) changes in personnel and job responsibilities; (b) lack of accessible and/or stand ardized data; (c) changes in software; and (d) changes in management processes, including outsourcing of some administrative functions.

\subsection{Procedures}

The analytical procedures used were based upon those proposed by the National Institute for Occupational Safety and Health (NIOSH) (Robson, Shannon, Goldenhar, \& Hale, 2001) and the guide to eval uating the effectiveness of training interventions developed by the National Centre for Vocational Education and Research (NCVER) (Doucouliagos \& Sgro, 2000).

However the focus of the procedures reported by Robson et al. (2001) was mostly on clear cut pre and post intervention compari sons; more subtle longitudinal techniques were only briefly discussed. Inferential techniques for rate ratios and rate differences were dis cussed, but it was pointed out that these techniques are only appro priate in the absence of trend in the historical data. Where trend is evident (as in the present case), the suggestion was to use regression techniques and in particular time series analysis using autoregressive integrated moving average (ARIMA) models to account for autocorre lation in the data.

The NCVER guide to evaluating the effectiveness of training interventions (Doucouliagos \& Sgro, 2000) presented a more thorough treatment of time series and multiple regression methods, which are appropriate when: (a) the intervention occurs in stages; (b) the response to the intervention is gradual; and (c) factors other than the intervention are also influencing the response variable. In a regression analysis to assess the impact of training, Doucouliagos and Sgro (2000) used dummy variables to separate the training effect from seasonal, autoregressive, and time trend effects. 
Table 1

Annual Estimates of Total Industry Equivalent Full Time Nursing Staff Based on Total Industry Remuneration

\begin{tabular}{|c|c|c|c|c|}
\hline Financial Year & Remuneration $\$ 10^{6}$ & Wage Index & Remuneration (Jun-03 $\$ 10^{6}$ ) & $\overline{\text { Estimated EFTNS }}$ \\
\hline $93-94$ & 1462.1027 & 0.6474 & 2258.3566 & 15801 \\
\hline $94-95$ & 1463.2157 & 0.6720 & 2177.3607 & 15235 \\
\hline $95-96$ & 1531.5596 & 0.6991 & 2190.8375 & 15329 \\
\hline $96-97$ & 1601.7399 & 0.7256 & 2207.3644 & 15445 \\
\hline $97-98$ & 1637.5036 & 0.7599 & 2154.7714 & 15077 \\
\hline $98-99$ & 1671.1480 & 0.7875 & 2122.1109 & 14849 \\
\hline $99-00$ & 1740.4297 & 0.8328 & 2089.9086 & 14624 \\
\hline $00-01$ & 2048.8351 & 0.8708 & 2352.8925 & 16461 \\
\hline 01-02 & 2217.2259 & 0.9225 & 2403.6134 & 16816 \\
\hline $02-03$ & 2424.9997 & 0.9688 & 2503.0298 & 17510 \\
\hline
\end{tabular}

Note. EFTNS= equivalent full time nursing staff.

A previous preliminary evaluation (DHS, 2002) as well as exam ining numbers of back injury claims, also considered other broader categories: (a) all claims; (b) manual handling claims associated with patient transfer and repetitive movement; and (c) all claims for sprains and strains of joints and adjacent muscles. In each case back injuries constituted the majority of claims, and similar patterns of change were reported in all cases. In light of this, the present study was based primarily on a longitudinal analysis of frequencies of claims for back injuries to nurses, and the corresponding claim incidence rates per 1,000 equivalent fulltime nursing staff (EFTNS). A supple mentary analysis compared trends in back injury data with trends in other classes of musculoskeletal injury.

The longitudinal methodology utilized both analysis of variance (ANOVA) and a time series approach involving multiple regression methods. The ANOVA approach extends the pre post comparisons made in the previous evaluation (DHS, 2002). The time series methodology is consistent with the approach described by Doucou liagos and Sgro (2000). Because comprehensive longitudinal staffing data were not available, a preliminary analysis was conducted to estimate EFTNS for those agencies/years where it was not known.

\section{Results and Discussion}

\subsection{Preliminary Analysis: Relationship between Remuneration, EFTNS, and Hours Worked}

The analysis was based on the 10 year period July 1993 June 2003. VWA provided claims data for this period, together with total remuneration figures for each agency by financial year (FY). All remuneration figures were re expressed in June 2003 dollars, using the Victorian Female Average Weekly Earnings index (Australian Bureau of Statistics, 2004).

In order to correct for the effects of a changing staffing base, calculation of standardized claims incidence rates was required. This required annual EFTNS for each agency for the 10 year period. Most agencies were unable to provide comprehensive data; 50 agencies supplied data for the financial years 20002001 to 2002 2003, but only four agencies provided data for all years. The correlations be tween the remuneration and staffing measures for each of the 10 years ranged from 0.9501 to 0.9999 . These data were used to develop a linear regression model describing the relationship between EFTNS and remuneration data supplied by VWA.

The fitted regression equation was:

Estimated EFTNS $=23.167+6.9864 \times$ Indexed Remuneration.

In the absence of comprehensive data, it was considered that with an $\mathrm{R}^{2}$ value of 0.94 this model was adequate for the purposes of estimating EFTNS. The equation was used to estimate EFTNS for each agency throughout the 10 year period.

Total industry EFTNS estimates for the stated financial years are shown in Table 1. A decline in estimated EFTNS from 15,800 in 1993
1994 to 14,624 in 1999 2000, followed by a marked increase in EFTNS in the ensuing 3 years, is apparent. The magnitude of the increase (3,000 EFTNS) corroborates claims by DHS that an extra 5,000 nurses were placed into health service centers across the state during this period. DHS estimated EFTNS to be 17,600 in 2005, which lends credence to the estimates obtained from this model.

\subsection{Longitudinal Analysis: Time Series and Multiple Regression Methods}

Because the claims data were sufficiently numerous to support a finer granularity than years, the longitudinal analysis was based on quarters. Quarterly estimates of EFTNS were obtained by linear inter polation of the annual estimates. Claims were allocated to quarters on the basis of the report date. The alternative of using date of injury was rejected because of the wide variation in the elapsed time between injury and report date. This, together with anecdotal evidence from a range of industry sources about a culture of carrying injuries, suggests that the interpretation of injury date is likely to vary from case to case, whereas report date is consistent and well defined. The effect of this decision is to treat claims resulting from recent injury events and claims resulting from aggravation of older injuries on the same basis.

Because there were relatively few claims from many of the smaller agencies, the data could not support a valid statistical analysis based on individual agencies. Hence the analysis was based on data aggre gated across all agencies. (i.e., total quarterly claims divided by total estimated quarterly EFTNS for all agencies). Fig. 1a shows the quarterly numbers of nurses back injury claims, and Fig. 1b shows the stand ardized figures (claims per 1000 EFTNS).

The VNBIPP was implemented progressively, both within indivi dual agencies and across the industry as a whole. The agency survey indicated that the earliest date of commencement was August 1998. By the end of September 1998, less than $10 \%$ of those that returned surveys had commenced. This figure had increased to $80 \%$ by De cember 2000. On the basis of this information, three periods were defined as follows: pre implementation September 1993 to Sep tember 1998; initial implementation December 1998 to December 2000; and ongoing March 2001 to June 2003, as indicated in Fig. 1b $\mathrm{b}^{1}$.

An initial statistical analysis of these data showed that there was statistically significant evidence of positive skew and heterogeneity of variance, violating the key assumptions of normal random error with constant variance. A standard strategy in such cases is to take logarithms of the dependent variable (Neter, Kutner, Nachtsheim, \& Wasserman, 1996). In this instance, the skew was sufficiently pro nounced that it was necessary to take logarithms twice ${ }^{2}$. Hence the

\footnotetext{
${ }^{1}$ The use of the terms "initial implementation" and "ongoing," rather than "implementation" and "post-implementation" reflects the fact that the VNBIPP is perceived as the initiation of a sustained shift in policies and practices, rather than a once only intervention. ${ }^{2}$ Another transformation commonly used in such circumstances is the reciprocal transformation. This produced almost identical results, but was not used because the order of the dependent variable is reversed, making results less intuitive when presented graphically.
} 
a

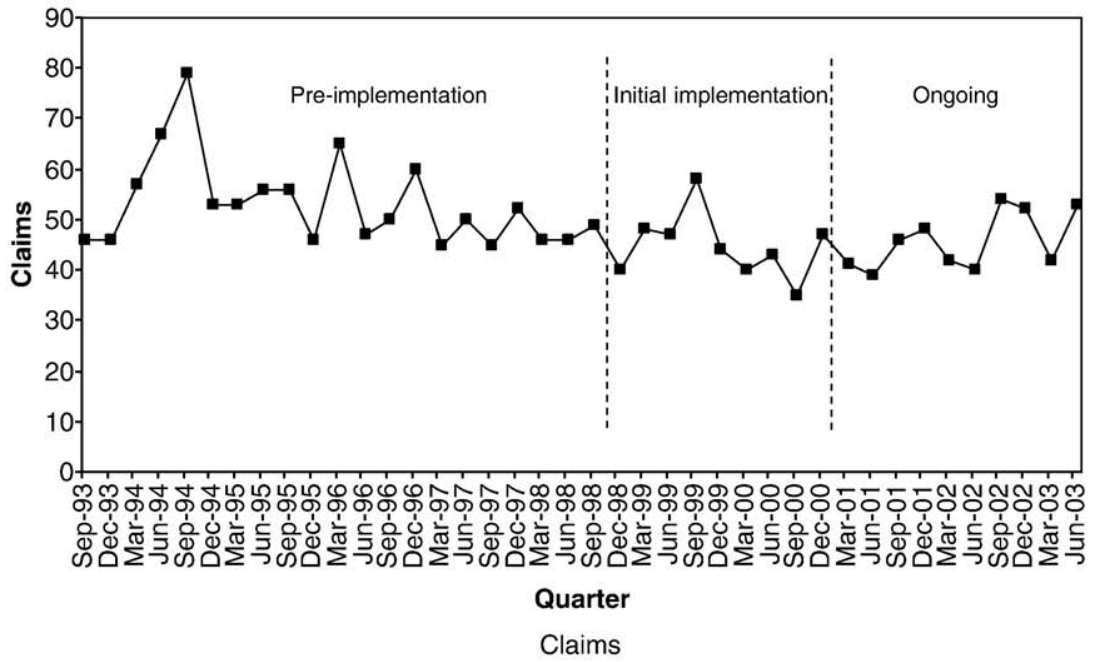

b

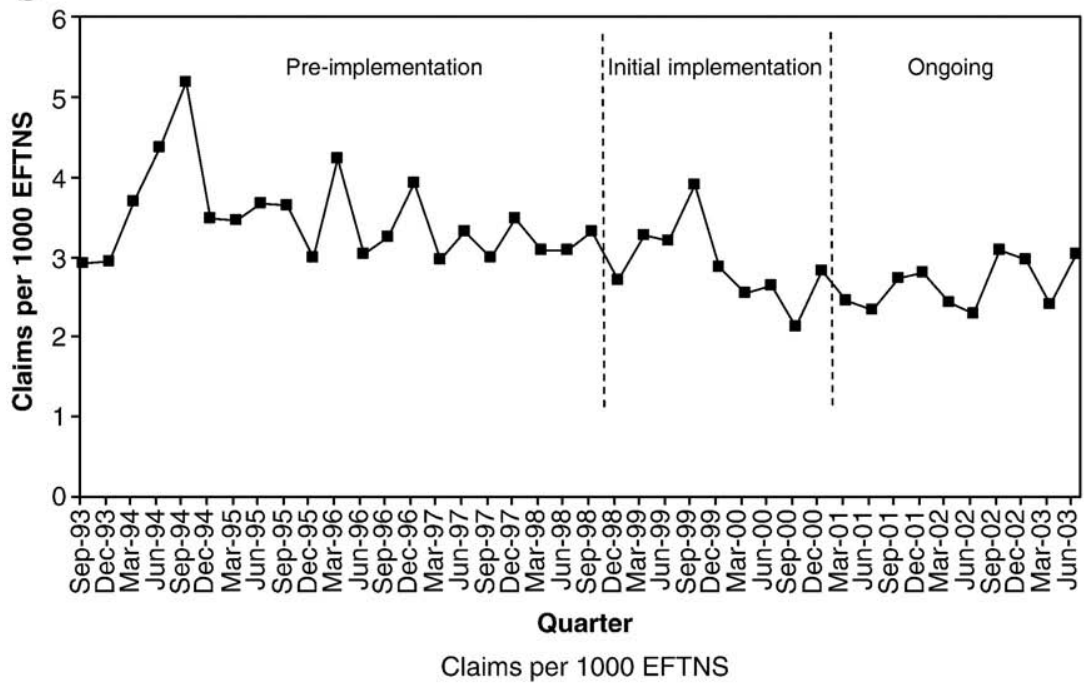

Fig. 1. Standard nurse back injury claims by quarter.

dependent variable for the subsequent analyses was $\log (\log$ (claims/ 1000 EFTNS)).

Initially, to facilitate comparison with the results from the previous preliminary evaluation (DHS, 2002), a one factor analysis of variance was carried out on $\log (\log$ (claims/1000 EFTNS $)$ ) for the three periods. There were statistically significant differences between the three defined time periods $(\mathrm{F}=13.38, \mathrm{p}<0.0005)$. There were significant reductions relative to the pre implementation period in both the implementation and ongoing periods, which supported the findings from the previous evaluation. The underlying rates of claims/1000 EFTNS for the defined time periods were estimated as: Sep 93 Sep 98: 3.41; Dec 98 Dec 00: 2.82; Mar 01 Jun 03: 2.62. The estimated reduction from pre implementation to the ongoing period was 0.79 claims/1000 EFTNS ( $95 \% \mathrm{CI}: 0.591 .01)^{3}$, representing a proportional reduction of $23.1 \%$ (95\% CI: $17.3 \% 29.6 \%$ ). However, such an analysis takes no account of any trend in the data within each period. To accommodate the effects of any trends, a segmented piecewise linear

\footnotetext{
${ }^{3}$ The change was estimated as the difference between point estimates produced by back transformation of the point estimates from the model for the transformed data. Upper and lower 95\% confidence limits for these changes were estimated respectively on the basis of the 2.5th and 97.5th percentiles of a simulated sample of 2000 such differences.
}

regression model (Neter et al., 1996) was fitted. The explanatory variables in this model included time (in quarters), to account for any initial trend in the pre intervention period, and also two indicators or "dummy variables" (Doucouliagos \& Sgro, 2000) to represent any differences in the slope of the trend line between the three designated periods. In accordance with standard time series methods (Makrida kis, Wheelwright, \& Hyndman, 1998), extra autoregressive terms were also investigated, but these made no improvement to the fit of the model. The resulting model conformed to the standard statistical assumptions; the residuals were normally distributed with con stant variance and no autocorrelation. The results are summarized in Table 2. The coefficient of quarter represents the initial trend, and the two trend change indicators $t c_{12}$ and $t c_{23}$ represent changes in trend differences in the slope of the trend line between the three designated periods. The fitted piecewise linear regression model is:

$$
\begin{aligned}
\log (\log (\text { claims } / 1000 \text { EFTNS }))= & 0.252 \quad 0.00183 \text { quarter } 0.0109 \text { tc }_{12} \\
& +0.0179 t_{23}
\end{aligned}
$$

The fitted model is overlaid on the data in Fig. 2, on both the log log scale (Fig. 2a, where each segment is linear) and back transformed onto the scale of the original data (Fig. 2b, where each segment is of exponential form and hence slightly curved). 
Table 2

Results of Piecewise-linear Regression of Transformed Claim Rate on Quarter

\begin{tabular}{lllll}
\hline Predictor & Coefficient & $\mathrm{SE}$ & $\mathrm{t}$ & $\mathrm{p}$ \\
\hline constant & -0.252 & 0.023 & $-11.03^{* * *}$ & $<0.001$ \\
quarter & -0.002 & 0.002 & -1.09 & 0.28 \\
tc12 & -0.011 & 0.005 & $-2.27^{*}$ & 0.03 \\
tc23 & 0.018 & 0.007 & $2.55^{*}$ & 0.02 \\
\hline
\end{tabular}

Note. tc $12=$ change in trend from period 1 to period 2 . tc $23=$ change in trend from period 2 to period 3

$* \mathrm{p}<0.05$. *** $\mathrm{p}<0.001$.

The regression model is a moderately good fit, explaining around half of the quarter to quarter variation in the transformed claim rates $\left(R^{2}=0.51\right)$. Statistically significant changes in claim rates occurred between each of the defined time periods. A slight downward trend is apparent in $\log (\log$ (claims/1000 EFTNS)) before the introduction of the VNBIPP (trend rate $=0.00183$ per quarter) but this was not statistically significant $(p=0.28)$. The greater variability of the claims rates in the earlier years is apparent in Fig. 2a. However the variability is asymmetrical the maximum quarterly value fell throughout the period while the minimum stayed stable. The apparent trend is attri butable to the greater variability (and specifically the higher maxima) in the earlier years. Whether there were any systematic causative factors underlying the reduction in variability throughout this period is unknown. However, regardless of this, the trend is greatly reduced (and is not statistically significant) after adjustment for the change in variability. As a consequence of this it is concluded that, notwith standing the possible existence of a prior trend, in the absence of any evidence of a reduction in the "floor" level of claim rates prior to Sep 98, it is reasonable to attribute any downward trend in claims rates since Sep 98 to the VNBIPP intervention.

During the initial implementation period, the downward trend in the transformed claim rate increased significantly in magnitude (change in trend $=0.0109, p=0.03$; new trend $=0.00180 .0109=0.0127$ ). In the post implementation period the downward trend in the transformed claim rate was reversed, to a statistically significant degree (change in trend $=+0.0179, \mathrm{p}=0.02$ ), resulting in a slight upward trend (new trend $=$

$0.0127+0.0179=+0.0052$ ); however this resulting trend was not statistically significantly different from zero. These results confirm that claim rates trended downward significantly during the initial imple mentation period. The estimated change in the underlying rate during this period was 0.78 claims/1000 EFTNS (95\% CI: 0.391 .18$)^{3}$, represent ing a proportional reduction of $23.9 \%$ (95\% Cl: $12.0 \% 36.2 \%$ ). There was some indication of a reactive reversal in the ongoing period after initial implementation, which potentially signifies a threat to sustainability of the gains made in the initial implementation period, although at the time of this study, the evidence for this was not conclusive. Two major factors identified by respondents to the survey of agencies as being barriers to future sustainability were lack of ongoing funding, both within facilities and from external sources, and physical constraints such as inappropri ate design and lack of storage space; other matters mentioned in connection with sustainability included resource issues, staffing issues, allocated time for program coordinators, staff complacency, and the need to maintain the momentum established by the VNBIPP.

\subsection{Comparison of Trends in Claims for Back Injuries and other Musculoskeletal Injuries}

It was suggested by members of the VNBIPP Advisory Committee that the benefits of reduced back injuries may be offset by increases in other types of injuries, due to changes in the approach to manual handling, poor maintenance of patient handling equipment, inappropri ate or inadequate storage of equipment, wrong floor coverings, and so forth. Conversely, a commensurate decrease in other types of muscu loskeletal injury would indicate that the reduction in back injuries may not be attributable to the No Lift program. An analysis of injuries to the elbow, wrist, knee, and ankle showed no significant evidence of changes in the rates of these injuries over the time frame of the study. There was a statistically significant increase in the rate of shoulder injuries; however, the increase was established before the VNBIPP intervention, and the rate of increase did not change significantly over the time frame of the study; hence it is considered that this increase, though unexplained, is unrelated to the intervention. From the point of view of attribution, there is no evidence that the reduction in back injuries during the time frame of the VNBIPP was either accompanied by concurrent reductions in other musculoskeletal injuries, or offset by commensurate increases in other musculoskeletal injuries.

\subsection{Limitations}

Caution must be exercised when interpreting the results of this longitudinal analysis. The validity of the analysis is limited by various factors that may distort the claims distributions across time in ways that are difficult or impossible to quantify. These include the effects of: (a) pre existing or chronic conditions; (b) staff mobility and changing skill mix; (c) health service re configurations; (d) casual employment through nursing agencies, and the consequent difficulty of assigning VWA claims to agencies; (e) changes in patterns of casual employment throughout the study period; (f) changes in policy governing ratios of nursing staff to patients; $(\mathrm{g})$ the extent of any industry culture of "carrying" low level injuries; (h) lags between injuries and claims; (i) the fact that common law claims tend to be larger in magnitude and

a

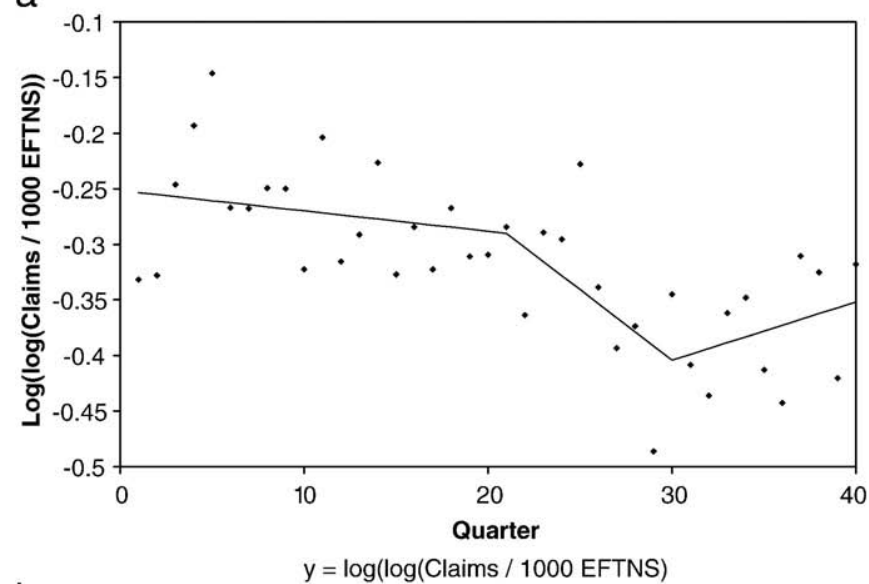

b

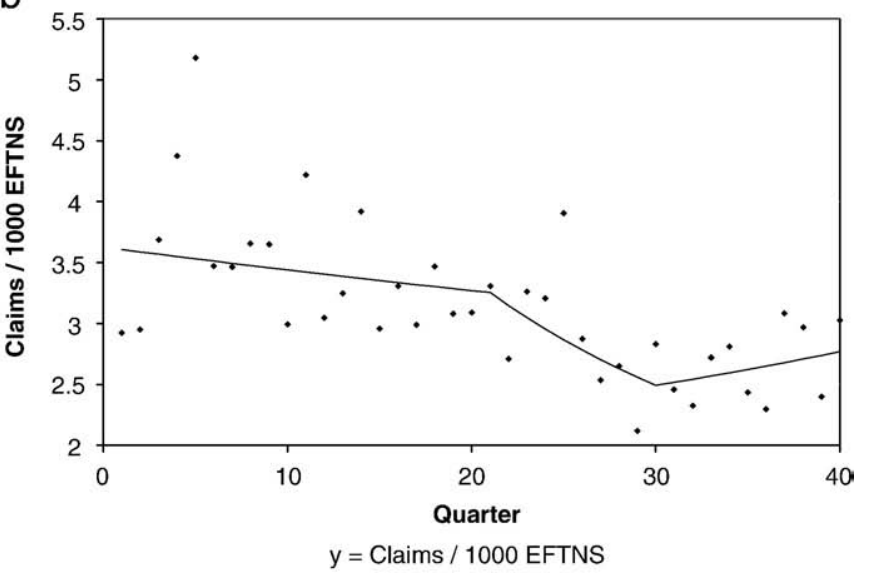

Fig. 2. Fitted piecewise-linear regression model. 
delayed for longer periods than standard claims; and (j) the lack of a clear indication in the VWA data that a claim has been finalized.

A major limitation was the variable availability and quality of agency specific data, which made it impossible to sharply define the scope of the intervention. The implicit inclusion in the analysis of wards that did not have VNBIPP funding to implement a No Lifting program would tend to dilute or attenuate the strength of the effect of the program in participating wards. The accuracy of the longitudinal analysis is also dependent on the accuracy of incidence rates, which had to be estimated on the basis of incomplete data supplied by a subset of agencies.

In terms of the methodological criteria of Shannon, Robson, and Guastello (1999), any before and after research design contains four inherent threats to internal validity (and hence to attribution), name ly: testing, instrumentation, history, and maturation.

Testing effects (changes in performance brought about by the measurement process itself) are not considered problematic in this study because the key measure was obtained indirectly through an existing reporting system. Instrumentation effects (changes in the method of measuring the outcome) would apply to changes in compensation rules and definitions. To the extent that these occurred during the period, adjustments were made in the VWA data supplied.

History and maturation effects relate to changes in performance that occur over time in the organizations due to factors other than the intervention. The best safeguard against these threats is comparison with a control group that does not receive the intervention. Wards where the intervention did not occur would have provided an ideal control group, but data were not available at ward level. In the absence of a control group, examination of trends before, during, and after an intervention provide a degree of validation against history and maturation effects. This was the main thrust of this study, supple mented by a quasi control comparison of the rates of back injury claims and claims for other classes of musculoskeletal injury. Together, these provide consistent support for attribution of the reduction in back injury claims to the VNBIPP intervention.

\section{Summary}

The primary longitudinal analysis employed was an analysis of standard claim incidence rates per 1,000 equivalent full time nursing staff (EFTNS). The methodology used both ANOVA and a time series approach involving multiple regression methods.

When the periods before and after initial implementation of the VNBIPP were compared, it was concluded that a statistically sig nificant reduction had occurred in mean quarterly standard back injury claim incidence rates per 1,000 EFTNS $(F=13.38, p<0.0005)$. Mean quarterly standard back injury claim rates were estimated to be 3.41 claims/1000 EFTNS before initial implementation and 2.62 claims/1000 EFTNS after initial implementation. This represents a $23.1 \%$ reduction in standard back injury claims/1000 EFTNS by nurses in public health service agencies in Victoria.

This result was further supported by examination of trends before, during, and after initial implementation. There was no statistically significant trend in quarterly back injury claim rates in the period before initial implementation of the VNBIPP. The claim rate declined at a statistically significant rate during the time of initial implementa tion, then stabilized at the new lower level in the period after initial implementation. The estimated change during the initial implemen tation period was 0.78 claims/1000 EFTNS, or $23.9 \%$. There was some indication (not statistically significant) of a reversal of the trend in the ongoing period, which potentially signifies a threat to sustainability of the gains made during the initial implementation period.

Apart from a steady increase in the rate of shoulder injuries throughout the whole study period, rates of other types of mus culoskeletal injury did not change significantly over the timeframe of the study, which provides further support for the attribution of the reduction in back injury claims to the effects of the VNBIPP.
Ergonomic principles encourage changing the work environment in order to suit the worker. Similarly, Australian legislation in occupational health and safety (e.g., Victorian Consolidated Regulations, 19994) requires that changes to physical work factors be explored as a priority over behavior based solutions. These Regulations are grounded in the safe design philosophy rather than the behavioral philosophy. The "hierarchy of control" problem solving model underlying such regula tions requires that "hazard elimination", "hazard substitution", "engi neering controls,' and "hazard isolation" should be sought above controls relying on safe behavior and the use of personal protective equipment (see Culvenor, 1997 for a review of the development of this model). The VNBIPP was an implementation of the high order safe design approach on an industry basis. The results demonstrate the success of this approach and show that it delivered a significant change in the immediate term, although there is some indication that sustainability in the longer term may be an issue.

\section{Impact on Industry}

This paper has shown that the VNBIPP brought about an estimated $23 \%$ reduction in the rate of standard back injury claims by nurses in public health service agencies in Victoria, indicating a substantial decline in the occurrence of a pervasive type of injury (Collins et al., 2004; Edlich, Winters, Hudson, Britt, \& Long, 2004; Engkvist, 2004) that is often seriously debilitating with prolonged effects (Edlich et al., 2005; Tate, Yassi, \& Cooper, 1992), and signifying a substantial improvement in the safety of a critical aspect of the work environment for nurses throughout the Victorian public health sector. The mag nitude of the reduction in the rate of injuries is not as great as those reported for some smaller scale nursing "no lift" interventions (Ash ford et al., 2003: 71\%; Collins et al., 2004: 61\%; OHSA, 2003: 45\%; Passfield et al., 2003: 38\%). Nevertheless, considering the often long latency periods associated with both the aetiology of back injuries and with the compensation claims process, and considering that this was a "translational" project in which an intervention was implemented across a whole health care system with varying degrees of institu tional commitment, capacity, and resourcing, rather than an "efficacy" trial with well motivated "volunteers," the demonstrated magnitude of the effect is substantial. The beneficial economic impact of the intervention will be demonstrated by means of a detailed cost benefit analysis to be presented in a forthcoming paper.

More generally, this paper demonstrates widely applicable analysis techniques for the longitudinal evaluation of OH\&S interventions, which are large in both organizational scope and temporal scale.

Finally, the authors wish to highlight an important over arching methodological issue with regard to the evaluation of any large scale intervention. This study was limited in ways that were avoidable; in particular, threats to precision and validity were brought about by the retrospective nature of the study and by the consequent incomplete ness and variable quality of the data that were available for use in the study. The authors are strongly of the view that, in order to enable an appropriate standard of quantitative evaluation of interventions in volving large investments of public funds, planning of the evaluation component and the associated data collection should be an integral part of the planning of an intervention, systematic data collection should be an integral part of the implementation of the intervention, and maintenance of appropriate records and compliance with re porting requirements should be an explicit condition of funding.

\section{Acknowledgements}

We acknowledge the staff from the Victorian health agencies who provided us with the data for this study, and the members of the

\footnotetext{
${ }^{4}$ Now superseded by the Occupational Health and Safety Regulations 2007 which are based on the same principles.
} 
Victorian Nurses Back Injury Prevention Project (VNBIPP) Advisory Committee, The Nurse Policy Branch of the Victorian Department of Human Services (DHS), and Victorian WorkCover Authority (VWA). We also acknowledge the collegial support of Dennis Else, Sally Wellard, John McDonald, David Borys and Cameron Hurst. The VNBIPP was a Victorian Government initiative and this research was performed under contract to DHS.

\section{References}

Ashford, M., Sdrinis, J., \& Doyle, C. (2003). Private Aged Care No Lifting Project Fina Report. Australian Nursing Federation Retrieved September 3, 2004, from http:/ www.anfvic.asn.au/pdfs/FinalRe1.pdf

Australian Nursing Federation (ANF) (Victorian Branch). (2003). No Lifting Policy, 2003. Retrieved March 15, 2003, from www.anfvic.asn.au

Australian Bureau of Statistics. (2004). Wage Cost Index Australia: March Quarter 2004 Cat. No. 6345.0 Canberra: Australian Bureau of Statistics.

Carlton, R. (1987). The effects of body mechanics instruction on work performance. The American Journal of Occupational Therapy, 41(1), 16-20.

Collins, J. W., Wolf, L., Bell, J., \& Evanoff, B. (2004). An evaluation of a "best practices" musculoskeletal injury prevention program in nursing homes. Injury Prevention, 10 , 206-211.

Culvenor, J. (1997). Breaking The Safety Barrier: Engineering New Paradigms In Safety Design. Unpublished Doctoral Thesis, Ballarat: University of Ballarat. Retrieved July 30, 2007, from www.culvenor.com

Department of Human Services [DHS]. (2002). Victorian Nurses Back Injury Prevention Project Evaluation Report 2002. Melbourne: Policy \& Strategic Projects Division, Victorian Government Department of Human Services.

Doucouliagos, C., \& Sgro, P. (2000). Enterprise Return on Training Investment. Adelaide Australia: National Centre for Vocational Education and Research Retrieved May 6 , 2003, from http://www.ncver.edu.au/publications/483.html

Edlich, R. F., Winters, K. L., Hudson, M. A., Britt, L. D., \& Long, W. B. (2004). Prevention of disabling back injuries in nurses by the use of mechanical patient lift systems. Journal of Long-Term Effects of Medical Implants, 14(6), 521-533.

Edlich, R. F., Hudson, M. A., Buschbacher, R. M., Winters, K. L., Britt, L. D., Cox, M. J., et al. (2005). Devastating injuries in healthcare workers: description of the crisis and legislative solution to the epidemic of back injury from patient lifting. Journal of Long-Term Effects of Medical Implants, 15(2), 225-241.

Engkvist, I. -L. (2001). Introduction of No Lift policy. In V. L. Blewett (Ed.), Workers Changing Work: lost leaders in organisational change. CD Proceedings of Work Congress 5, Working Safely in a Changing World. Adelaide: WorkCover Corporation.

Engkvist, I. -L. (2004). The Accident Process Preceding Back Injuries among Australian Nurses. Safety Science, 42, 221-235

Engkvist, I. -L., Hagberg, M., Linden, A., \& Malker, B. (1992). Over-exertion back accidents among nurses' aides in Sweden. Safety Science, 15(2), 97-108.

Feletto, M., \& Graze, W. (1997). A Back Injury Prevention Guide for Health Care Providers. Cal/ OSHA Consultation Service, Education and Training Unit, Sacramento, CA. Retrieved March 120, 2003, from www.dir.ca.gov/dosh/dosh_publications/backinj.pdf

Gaetjens, J. (2003). Workplace Environment Study. Adelaide: WorkCover Corporation of South Australia.

Garg, A. (1999). Evaluation of Long-Term Effectiveness of 'Zero-Lift Program' in Seven Nursing Homes and One Hospital. Washington, DC: National Institute for Occupational Safety and Health.

Garg, A., Owen, B. D., \& Olsen, B. (1992). An ergonomic evaluation of nursing assistants' jobs in a nursing home. Ergonomics, 35(9), 979-995.

Garrison, A. (1998). Princess Alexandra Hospital and District Health Service Manua Handling Project (Spinal Injuries Unit) Final Report. Proceedings of the Australian Nursing Federation (Victorian Branch) 'No Lifting' Expo, April 1998.

Gorman, M. (1998). Case study - a change in the approach to patient manual handling in a Brisbane hospital. Proceedings of the Australian Nursing Federation (Victorian Branch) 'No Lifting' Expo, April 1998.
Krause, T. R., Seymour, K. J., \& Sloat, K. C. M. (1999). Long-term evaluation of a behaviorbased method for improving safety performance: A meta-analysis of 73 interrupted time-series replications. Safety Science, 32, 1-18.

Makridakis, S., Wheelwright, S., \& Hyndman, R. (1998). Forecasting: Methods and Applications, (3rd Ed.). New York: Wiley.

Neter, J., Kutner, M., Nachtsheim, C., \& Wasserman, W. (1996). Applied linear statistical models, (4th. ed.). Chicago: Irwin.

Occupational Safety and Health Administration [OSHA]. (2003). Guidelines for Nursing Homes: Ergonomics for the Prevention of Musculoskeletal Disorders. Washington, DC: Author

Passfield, J., Marshall, E., \& Adams, R. (2003). No Lift Patient Handling Policy Implementation and Staff Injury Rates in a Public Hospital. Journal of Occupational Health and Safety - Australia and New Zealand, 19(1), 73-85.

Robson, L. S., Shannon, H. S., Goldenhar, L. M., \& Hale, A. R. (2001). Guide to Evaluating the Effectiveness of Strategies for PreventingWork Injuries: How to Show Whether a Safety Intervention Really Works. Washington, DC: Department Of Health And Human Services, Public Health Service, Centers for Disease Control and Prevention, National Institute for Occupational Safety and Health. Pub. No. 2001-119. Retrieved March 14, 2003, from www.iwh.on.ca

Royal College of Nursing. (1999). Code of Practice for Patient Handling. London: Royal College of Nursing Retrieved August 28, 2006, from http://www.rcn.org.uk/ publications/pdf/code-practice-patient-handling.pdf\#search=\%22RCN\%20\%22Code \%20of\%20Practice\%20for\%20Patient\%20Handling\%22\%201999\%22

Royal College of Nursing. (1999). Introducing a Safer Handling Policy. London: Royal College of Nursing Retrieved August 28, 2006, from http://www.rcn.org.uk/members/downloads/ intro_safer_pat_hand.pdf\#search=\%22RCN\%20\%22Introducing\%20a\%20Safer\% 20Patient\%20Handling\%20Policy\%22\%201999\%22

Shannon, H. S., Robson, L. S., \& Guastello, S. J. (1999). Methodological criteria for evaluating occupational safety intervention research. Safety Science, 31, 161-179.

Tate, R. B., Yassi, A., \& Cooper, J. (1992). Predictors of time loss after back injury in nurses. Spine, 24, 1930-1935.

Victorian Consolidated Regulations. (1999). Occupational Health and Safety (Manual Handling) Regulations 1999. Victoria: Author Retrieved December 7, 2006, from http://www.dms.dpc.vic.gov.au/Domino/Web_Notes/LDMS/PubLawToday.nsf/0/ 03fd96bb1791e08aca256e5b0003a79c/\$FILE/99-84sr001doc.doc

Peter Martin MEd is a senior lecturer in applied statistics in the School of Information Technology and Mathematical Sciences at the University of Ballarat. He has extensive experience of industrial training in statistical techniques for product design, process control, quality management, and occupational health and safety management.

Jack Harvey $\mathrm{PhD}$ is a senior research fellow in the School of Human Movement and Sport Sciences at the University of Ballarat. He is an applied statistician with extensive research experience in a wide range of science and engineering contexts, including the design and evaluation of interventions in the fields of physical activity, health promotion, occupational preparedness, and occupational health and safety.

John Culvenor PhD is a consulting engineer specializing in workplace safety and ergonomics, and a senior lecturer and senior research fellow at the University of Ballarat. Dr Culvenor works with public companies, law firms and state and federal authorities on workplace hazard analysis and design, expert witness opinions, training, teaching, policy development and research. His special interests include safe design, new thinking/creative thinking and hazard areas including manual handling, plant and equipment, and fall prevention.

Warren Payne PhD is Professor of Human Movement Science at the University of Ballarat. He is an exercise physiologist with extensive research experience including work with elite athletes in the fields of rowing, cycling, badminton and swimming, and workers involved in heavy manual trades including sheep shearing, fire fighting, aircraft baggage handling, building trades, and military combat trades. 